ADVANCE RESEARCH JOURNAL OF SOCIAL SCIENCE
$\begin{gathered}\text { AClume 10 | Issue 2 | December, 2019 | 79-84 } \\ \text { STUDY }\end{gathered}$
ISSN-0976-5611
DOI: 10.15740/HAS/ARJSS/10.2/79-84

\title{
Women evolving roles in substance abuse: Reason and consequence
}

Jasbir Kaur

G. H.G. Insititute of Law for Women, Sidhwan Khurd, Ludhiana (Punjab) India (Email : sainijasbir73@gmail.com)

\section{ARTICLE INFO :}

Received : 07.10 .2019

Accepted : 29.11.2019

\section{KEY WORDS :}

Women evolving roles, substance abuse, Reason, Consequence

HOW TO CITE THIS ARTICLE :

Kaur, Jasbir (2019).Women evolving roles in substance abuse: Reason and consequence. Adv. Res. J. Soc. Sci., 10 (2) : 79-84, DOI: 10.15740/HAS/ARJSS/ 10.2/79-84. Copyright@2019 : Hind Agri -Horticultural Society

\begin{abstract}
In past decade the substance abuse mainly by the males in the societies. Historically, women using substance have always been frowned upon. Rules on acceptability dates back as far as laws of Hammurabi in the west and the Manusmriti in India which states that, "A wife who drinks wine ... may be abandoned at any time." But with the pass of time women more indulged in substance abuse. The reasons are basically loneness, peer pressure, family relation and biological factor responsible. In present we will surprised to see women rehab centre that show how much women involved in drug abuse. The women used as carrier for drug transportation, female selling them self for the sake of drugs. It's time to think for drug menace in female. In this efforts to show the real picture of female drug abuse.
\end{abstract}

